\title{
Dysfunction of the thymus in mice with hypertension
}

\author{
XIANLIANG DAI, SHUAIBO HUANG, ZHIQING HE, FENG WU, \\ RU DING, YIHONG CHEN, CHUN LIANG and ZONGGUI WU
}

\begin{abstract}
Department of Cardiology, Changzheng Hospital, The Second Military Medical University, Shanghai 200003, P.R. China
\end{abstract}
Received September 17, 2015; Accepted November 4, 2016

DOI: 10.3892/etm.2017.4125

\begin{abstract}
The aim of this study was to evaluate thymus function in mice with hypertension. A total of $60 \mathrm{C} 57 \mathrm{BL} / 6 \mathrm{~J}$ mice were randomized into control, sham surgery and two-kidney, one-clip groups ( $n=20$ in each). At 4 or 8 weeks after surgery, mice were sacrificed, and blood, spleens, kidneys and thymuses were harvested. The results of reverse transcription-quantitative polymerase chain reaction analysis revealed that the mRNA levels of Forkhead box protein N1 (Foxn1) and autoimmune regulator (AIRE) in the thymus tissue of mice from the HTN group were significantly lower than those from the control group at 4 and 8 weeks $(\mathrm{P}<0.05)$. Foxn1 and AIRE expression was also reduced in the sham surgery group at 4 weeks after surgery, but had recovered 4 weeks later. Similar results were observed for the expression of signal-joint $\mathrm{T}$ cell receptor excision circles and the percentages of $\mathrm{T}$ cell subsets. The present study indicates that impaired thymus function is associated with hypertension in mice, which suggests that thymus function may be a novel target for the treatment of patients with hypertension.
\end{abstract}

\section{Introduction}

Hypertension is a multifactorial disease associated with various types of cells and affected by multiple factors $(1,2)$. It is characterized by elevated arterial pressure, and may be complicated by damage to the heart, blood vessels, brain, kidneys, retinas and other target organs, and metabolic changes in systemic disease (3). Patients with hypertension exhibit an increased incidence of heart and cerebrovascular disease and associated mortality; therefore, the ultimate goal

Correspondence to: Professor Chun Liang or Professor Zonggui Wu, Department of Cardiology, Changzheng Hospital, The Second Military Medical University, 415 Fengyang Road, Shanghai 200003, P.R. China

E-mail: chunliangliang@hotmail.com

E-mail:wu_zonggui@yeah.net

Key words: two-kidney one-clip, hypertension, thymus atrophy, dysfunction, signal-joint $\mathrm{T}$ cell receptor rearrangement excision circle of antihypertensive therapy is to reduce these risks by controlling blood pressure (4).

In 1970, Ebringer and Doyle reported that $30 \%$ of patients with hypertension exhibited increased serum immunoglobulin levels (5) and, with the rapid development of clinical immunology, it has been demonstrated that hypertension is associated with immune dysfunction, which suggests that immune factors are associated with the complications of hypertension (6). Previous studies have revealed that $\mathrm{T}$ cells are able to induce high blood pressure, vascular disorders and kidney disease and that possible mechanisms for this may include the release of cytokines, which directly affect vascular and renal function or indirectly stimulate cells to release additional cytokines, and induce the infiltration of inflammatory cells $(7,8)$. The thymus is a primary immune organ, in which $\mathrm{T}$ cells are generated and matured (9); therefore, high blood pressure is likely to be associated with thymus function. A recent study has revealed that the thymus atrophies and becomes dysfunctional with age (10). A thymus transcription factor, Forkhead box protein N1 (Foxn1) is an important factor for complete physiological function of the thymus (11). As the thymus atrophies, the expression of the thymus aging-associated gene Foxn1 decreases, leading to a downregulation of Foxn1 with age (12). Increased expression of Foxn1 has been shown to improve thymus function, and potentially promote regeneration of the thymus (13), suggesting that Foxn1 may serve a role in high blood pressure. A previous study reported that atrophy of the thymus was observed in mice with hypertension (14); however, the specific changes in thymus function remain to be elucidated.

The autoimmune regulator (AIRE) is expressed in the thymus, particularly in thymic medullary epithelial cells. The expression profile of peripheral tissue antigens is affected by AIRE (15), and AIRE expression levels have been shown to have functional effects in the thymus (16).

The thymus is a vital immune organ, serving an important role in human health. With increasing age, the thymus gradually shrinks and its functionality declines or is lost completely (17). Thymus function may be used as a proxy to indicate the condition of a patient's immune system to a certain degree. At the $\mathrm{CD}^{-\mathrm{CD}} 8^{-}$-phase, thymocytes begin the rearrangement of their T cell receptor (TCR) $\alpha$ chain, and $95 \%$ of T cells are TCR $\alpha \beta$ (18). The signal-joint (sj) TCR excision circle (TREC) is an extra-chromosomal DNA fragment ring, which is generated when the TCR $\delta$ gene is deleted prior to TCR $\alpha$ gene rearrangement. It is stable but not replicated, so 
with increased cell generation and dilution, the level of sjTREC is highest in $\mathrm{T}$ cell populations most recently generated, and is lower in cell groups after the cell division cycle (19-21). The prevalence of sjTREC therefore provides an indication of the number of naive T cells during functional TCR formation. The presence of naive $\mathrm{T}$ cells, which enable the immune system to recognize all antigens, serves as an indicator of the generation and output of T cells; therefore, the level of sjTREC may reflect the functional status of the thymus $(22,23)$.

To date, research into hypertension has predominantly focused on the changes in the renin-angiotensin system $(24,25)$, with less investigation of changes in immune mechanisms and organs being performed. Investigating the changes to immune organs in patients with hypertension may identify a novel target for the treatment of hypertension through immune function.

\section{Materials and methods}

Animals. A total of 60 8-week-old C57BL/6J male mice with a mean weight of $20 \mathrm{~g}$ were purchased from Shanghai SLAC Laboratory Animal Co., Ltd. (Shanghai, China). Animals were housed in a climate-controlled, light-regulated space with 12-hour day and night cycles. They were fed a normal mouse chow and water ad libitum. Animal protocols were approved by the ethics committee of Second Military Medical University (Shanghai, China), and performed according to the Guide for the Care and Use of Laboratory Animals published by the United States National Institutes of Health (NIH Publication no. 85-23, revised 1996).

Induction of two-kidney, one-clip hypertension. Following 1 week of acclimation, mice were randomly divided into the control, sham surgery and two-kidney, one-clip (HTN) groups ( $n=20$ in each). As previously described (26), the mice in the sham surgery and HTN groups were anesthetized with sodium pentobarbital (50 mg/kg; intraperitoneally; cat. no. P3761; Sigma-Aldrich; Merck Millipore, Darmstadt, Germany) the left kidney was exposed via flank incision, renal arteries were separated and a silver clip was placed around the left renal artery. Mice in the sham surgery group underwent an identical surgical procedure with the exception of the arterial clip. At 4 weeks post-surgery, 10 mice from each group were fasted overnight, anesthetized with sodium pentobarbital $(50 \mathrm{mg} / \mathrm{kg}$; intraperitoneally) and sacrificed via carotid puncture. The remaining mice were fasted overnight and sacrificed as above at 8 weeks post-surgery. Blood samples were harvested from the carotid artery, and organs of interest (spleen, kidneys and thymus) were immediately harvested, blotted dry, weighed and stored at $-80^{\circ} \mathrm{C}$ until required. Blood samples and spleens were prepared as previously described $(27,28)$, and organ indices were calculated using the following formula: Organ index=organ weight/body weight $\mathrm{x} 1,000$.

Measurement of blood pressure. The systolic blood pressure (SBP) and diastolic blood pressure (DBP) of mice in each group were measured weekly using a non-invasive computerized tail-cuff system (ALC-NIBP; Shanghai Alcott Biotech Co., Ltd., Shanghai, China). The SBP and DBP of each mouse were measured three times and the mean was calculated.
DNA and RNA extraction, and reverse transcription-quantitative polymerase chain reaction ( $R T-q P C R)$. Total RNA was extracted from the thymus of each mouse using TRIzol reagent. The purity of obtained RNA was estimated using a NanoDrop 2000c spectrophotometer (Thermo Fisher Scientific, Inc., Wilmington, DE, USA), and RNA with an A260/A280 ratio $>1.8$ was used for cDNA synthesis. First strand cDNA synthesis was performed using the First Strand cDNA Synthesis kit (cat. no. 6210A; Takara Bio, Inc., Otsu, Japan) according to the manufacturer's protocol. qPCR was performed using SYBR Green PCR Master Mix iQ (cat. no. 170-8882AP; Bio-Rad Laboratories, Inc., Hercules, CA, USA) and the CFX Connect Real-Time PCR System (Bio-Rad Laboratories, Inc., Hercules, CA, USA), according to the manufacturer's protocols. qPCR conditions were as follows: $3 \mathrm{~min}$ at $95^{\circ} \mathrm{C}$, followed by two-step PCR at $95^{\circ} \mathrm{C}$ for $10 \mathrm{sec}$ and $58^{\circ} \mathrm{C}$ for $30 \mathrm{sec}$ for 50 cycles, with fluorescence monitoring at the end of each elongation step. All primers were obtained from Thermo Fisher Scientific, Inc. (Waltham, MA, USA), and are listed in Table I. Relative mRNA expression of target genes was calculated using the $2^{-\Delta \Delta C q}$ method (29). Target sequences were normalized to $\beta$-actin in multiplexed reactions performed in duplicate.

Quantification of TRECs. Genomic DNA was extracted from thymocytes using the Wizard Genomic DNA Purification kit (cat. no. A1125; Promega Corporation, Madison, WI, USA). qPCR was performed using a CFX Connect real-time PCR System (Bio-Rad Laboratories, Inc.) to detect the number of TRECs. Each amplification was performed using SYBR-Green PCR Master Mix iQ (cat. no. 170-8882AP; Bio-Rad Laboratories, Inc.) according to the manufacturer's protocol. The PCR conditions were as follows: $5 \mathrm{~min}$ at $95^{\circ} \mathrm{C}$, followed by three-step PCR: $95^{\circ} \mathrm{C}$ for $15 \mathrm{sec}, 60^{\circ} \mathrm{C}$ for $40 \mathrm{sec}$ and $72^{\circ} \mathrm{C}$ for $30 \mathrm{sec}$ for 45 cycles, with fluorescence monitoring at the end of each elongation step. PCR data was analyzed using SDS software (version 2.2.3; Applied Biosystems; Thermo Fisher Scientific, Inc.). The PCR product of sjTREC and recombination activating protein $2\left(\mathrm{RAG}_{2}\right)$ sequence was cloned into the PCR3.1 plasmid (Invitrogen; Thermo Fisher Scientific, Inc.) at known concentrations: $10^{6}, 10^{5}, 10^{4}, 10^{3}$ and $10^{2}$ copies $/ \mu 1$. Target sequences were normalized to $\beta$-actin in multiplexed reactions performed in duplicate. Each sample was performed in triplicate and the data expressed as the number of copies of sjTREC $/ 10^{5}$ cells based on the mouse genome of $2.6 \times 10^{9}$ bp (30). All primers were obtained from Thermo Fisher Scientific, Inc., and primer sequences are displayed in Table I.

Flow cytometric analysis. Blood cells and splenocytes were incubated with the appropriate antibodies as previously described $(31,32)$ and flow cytometry was performed using a FACSCalibur cell analyzer (BD Biosciences, Franklin Lakes, NJ, USA). Antibodies (all BioLegend, Inc., San Diego, CA, USA) used are as follows: Alexa Fluor 488 anti-mouse CD3 (cat. no. 100210), PreCP/Cy5.5 anti-mouse CD4 (cat. no. 100540), Alexa Fluor 647 anti-mouse/human CD44 (cat. no. 103018) and PE anti-mouse CD62 L (cat. no. 104408). All antibodies were used at a dilution of 1:12. Data were analyzed using FlowJo software, (version 10.0.7; Tree Star, Inc., Ashland, OR, USA). 
Table I. Oligonucleotide primers used for reverse transcription-quantitative polymerase chain reaction.

\begin{tabular}{lll}
\hline Gene & \multicolumn{1}{c}{ Forward } & \multicolumn{1}{c}{ Reverse } \\
\hline m $\beta$-actin & 5'-GGTCATCACTATTGGCAACG-3' & 5'-ACGGATGTCAACGTCACACT-3' \\
m Foxn1 & 5'-TGACGGAGCACTTCCCTTAC-3' & 5'-GACAGGTTATGGCGAACAGAA-3' \\
m AIRE & 5'-GGTTCCTCCCCTTCCATC-3' & 5'-GGCACACTCATCCTCGTTCT-3' \\
m sjTREC $_{\mathrm{m} \mathrm{RAG}_{2}}$ & 5'-CATTGCCTTTGAACCAAGCTG-3' & 5'-TTATGCACAGGGTGCAGGTG-3' \\
& 5'-TGACGTGGTGTATAGTCGA-3' & 5'-TCCTGAAGTTCTGGGAGA-3'
\end{tabular}

m, murine; Foxn1, forkhead box protein N1; AIRE, autoimmune regulator; sjTREC, signal joint T cell receptor excision circle; RAG2, recombination activating gene 2 .

A

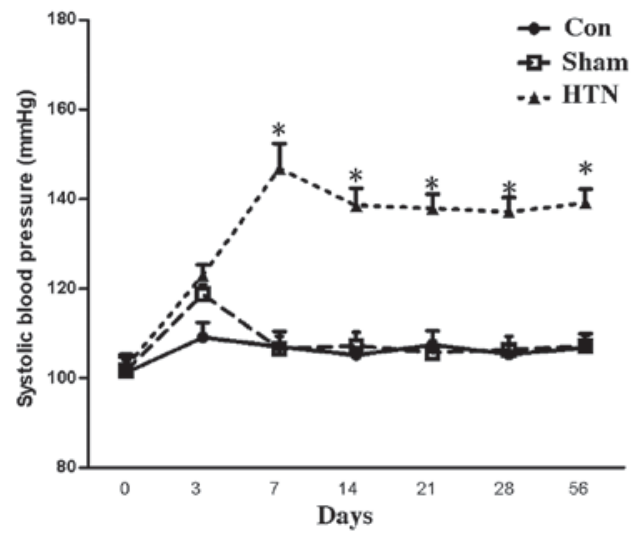

B

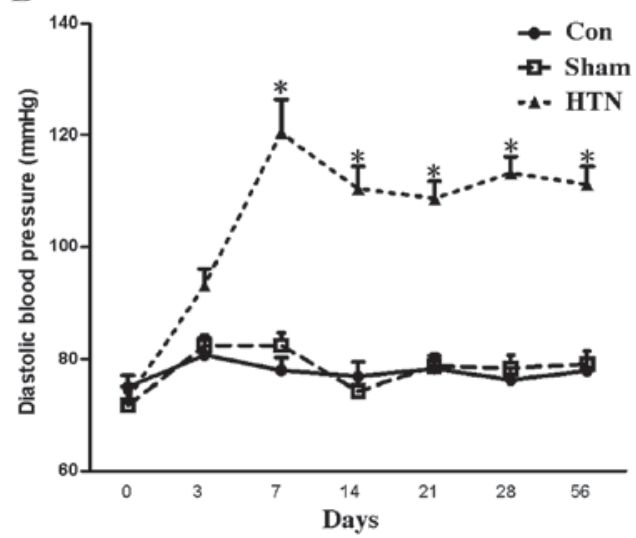

Figure 1. (A) Systolic and (B) diastolic blood pressure in the con, sham and HTN groups. Data are presented as the mean \pm standard error of the mean, $\mathrm{n}=10$. ${ }^{*} \mathrm{P}<0.05$ vs. con. Con, control group; sham, sham surgery; HTN, two-kidney, one-clip hypertension group.

Hematoxylin and eosin $(H \& E)$ staining. Standard $\mathrm{H} \& \mathrm{E}$ staining was performed according to the manufacturer's protocol (Beijing Xin Hua Luyuan Science and Technology, Ltd., Beijing , China), and viewed under an Olympus IX51 fluorescence microscope (OLYMPUS CORPORATION, Japan).

Statistical analysis. Data are presented as the mean \pm standard error of the mean. Data analysis was performed using Student's $t$-test for comparison between two groups and one-way analysis of variance was performed to test for differences among multiple groups, followed by Fisher's least significant difference test using SPSS 19.0 (IBM SPSS, Armonk, NY, USA). $\mathrm{P}<0.05$ was considered to indicate a statistically significant difference.

\section{Results}

Blood pressure. At 4 weeks post-surgery, the SBP and DBP of the HTN group were significantly increased $(\mathrm{P}<0.001)$ compared with those of the sham and control groups, and reached the hypertension criteria (SBP >140 $\mathrm{mmHg}$; Fig. 1) (27), indicating that the hypertensive models were successfully established.

Changes in thymus function. Organs of interest (spleen, kidneys and thymus) were immediately removed following sacrifice and the organ indices were calculated. Thymus atrophy was observed in the HTN group as illustrated in Fig. 2A-C. The thymic index of the HTN group exhibited no significant differences at 4 or 8 weeks post-surgery compared with the control and sham groups (Table II).

H\&E staining of the thymus revealed stereotypical deterioration of the thymic epithelial compartment, reduced distinction between the cortical and medullary regions and a reduction in the number of medullary islets per thymic lobe in the HTN group (Fig. 2D-F).

At 4 and 8 weeks post-surgery, the expression of Foxn 1 and AIRE mRNA in the thymus was significantly downregulated (4 weeks, Foxn1 and AIRE, $\mathrm{P}<0.001 ; 8$ weeks, Foxn1 $\mathrm{P}<0.001$ and AIRE $\mathrm{P}<0.05)$ in the HTN group compared with the control group (Fig. 2G and H). There was no significant difference in the expression of Foxn1 and AIRE mRNA at 8 weeks post-surgery between the sham and HTN groups; however, there was a significant difference $(\mathrm{P}<0.001)$ between the sham and control groups at 4 weeks post-surgery. Patterns of sjTREC expression were similar to those of Foxn1 and AIRE, as shown in Fig. 2I and J. Expression of sjTREC in the thymus was significantly downregulated in the HTN group compared with the control group at 4 and 8 weeks post-surgery (both $\mathrm{P}<0.001)$, and a significant difference $(\mathrm{P}<0.001)$ was observed between the sham and HTN groups at 8 weeks post-surgery. Furthermore, a significant difference $(\mathrm{P}<0.001)$ was observed between the control and sham groups at 4 weeks post-surgery. 
Table II. Body, thymus and spleen weight, and thymus index of mice.

\begin{tabular}{|c|c|c|c|c|c|c|}
\hline \multirow[b]{2}{*}{ Parameters } & \multicolumn{2}{|c|}{ Control group } & \multicolumn{2}{|c|}{ Sham group } & \multicolumn{2}{|c|}{ HTN group } \\
\hline & Wk $4(n=10)$ & Wk $8(n=10)$ & Wk $4(n=10)$ & Wk $8(n=10)$ & Wk $4(n=10)$ & Wk $8(n=10)$ \\
\hline Body weight, g & $21.11 \pm 0.82$ & $26.32 \pm 3.62$ & $20.32 \pm 0.76$ & $25.67 \pm 1.99$ & $20.40 \pm 1.22$ & $26.33 \pm 2.17$ \\
\hline Thymus weight, g & $0.043 \pm 0.051$ & $0.039 \pm 0.011$ & $0.038 \pm 0.0029$ & $0.037 \pm 0.0061$ & $0.041 \pm 0.0071$ & $0.038 \pm 0.008$ \\
\hline Spleen weight, g & $0.079 \pm 0.013$ & $0.087 \pm 0.02$ & $0.076 \pm 0.0058$ & $0.079 \pm 0.004$ & $0.084 \pm 0.0097$ & $0.086 \pm 0.0082$ \\
\hline Thymus index & $1.83 \pm 0.475$ & $1.588 \pm 0.374$ & $1.818 \pm 0.266$ & $1.506 \pm 0.22$ & $1.834 \pm 0.354$ & $1.575 \pm 0.225$ \\
\hline
\end{tabular}

Values are expressed as the mean \pm standard error of the mean. Wk, weeks post-surgery; HTN, 2-kidney, 1-clip hypertension.
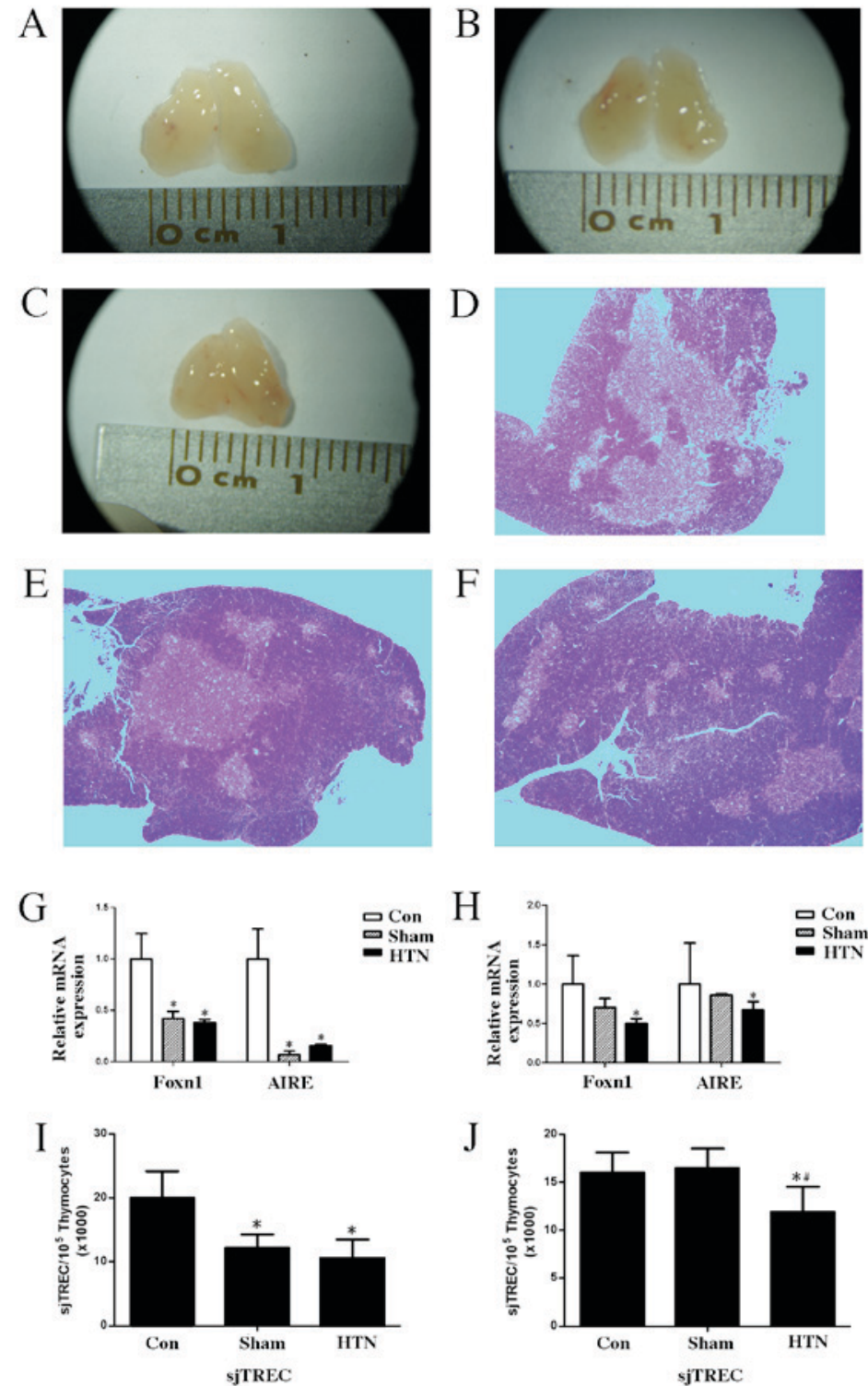

Figure 2. Changes in thymus function. Harvested thymuses from animals in the (A) con, (B) sham and (C) HTN groups. Hematoxylin and eosin staining of thymus tissue (magnification, x40) from (D) con, (E) sham and (F) HTN mice. Relative expression of thymus Foxn1 and AIRE at (G) 4 weeks and (H) 8 weeks post-surgery. Expression of thymus sjTREC at (I) 4 weeks and (J) 8 weeks post-surgery. Data are presented as the mean \pm standard error of the mean, $\mathrm{n}=10$.

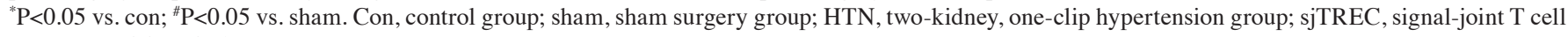
receptor excision circle.

Changes in T cell subsets evaluated by flow cytometry. Flow cytometric analysis was performed on blood and splenocytes, as shown in Fig. 3A and B. Significant differences were observed between the $\mathrm{T}$ cell subset percentages in the blood 
A

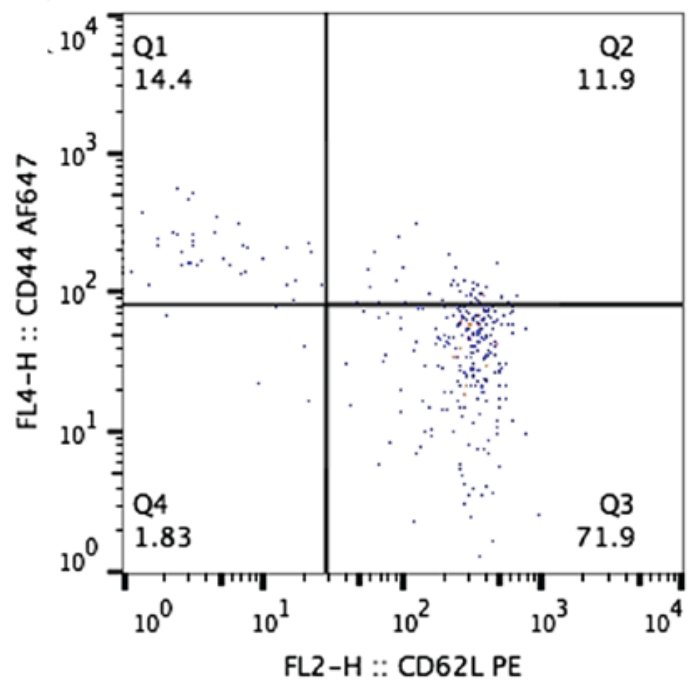

C

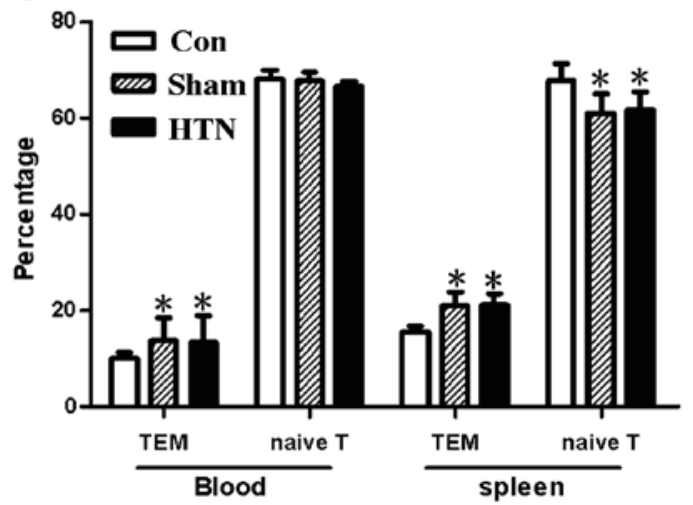

$\mathrm{B}$

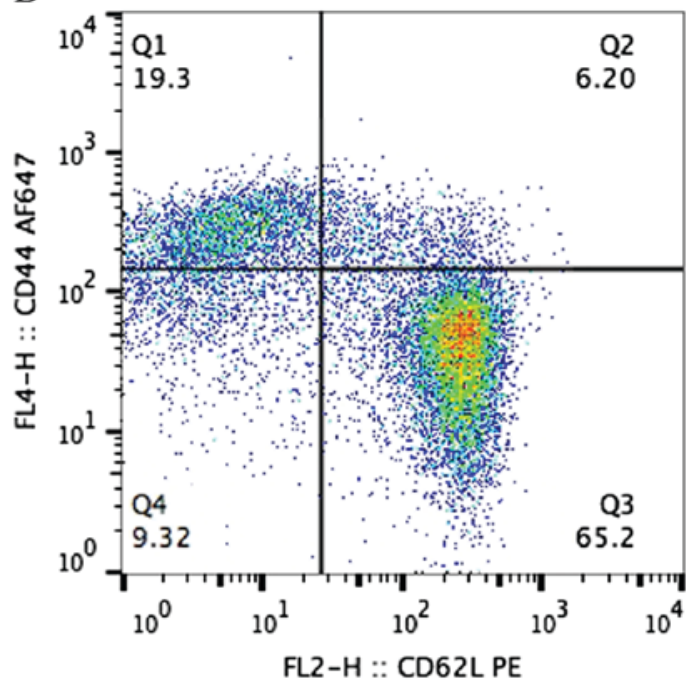

$\mathrm{D}$

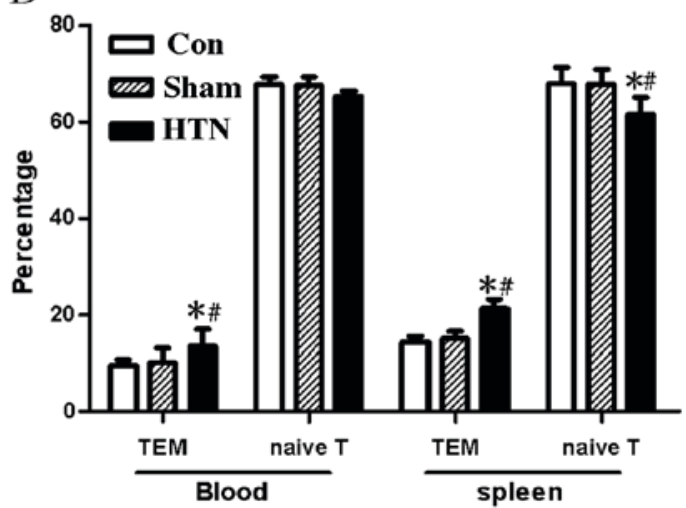

Figure 3. Changes in T cell subsets measured by flow cytometry. Blood and splenocyte flow cytometric analysis at (A) 4 weeks and (B) 8 weeks post-surgery. Changes in the percentages of $\mathrm{T}$ cell subsets at (C) 4 weeks and (D) 8 weeks post-surgery. Values are expressed as the mean \pm standard error of the mean, $\mathrm{n}=10$. ${ }^{*} \mathrm{P}<0.05$ vs. con; ${ }^{\text {P }}<0.05$ vs. sham. Con, control group; sham, sham surgery group; HTN, 2-kidney, 1-clip hypertension group; TEM, effector memory T cell.

and splenocytes of the control group compared with the other groups at 4 weeks post-surgery [blood and splenocytes, effector memory $\mathrm{T}$ cells (TEM) $\mathrm{P}<0.001$; splenocytes, naïve $\mathrm{T}$ cells $\mathrm{P}<0.05]$, whereas there was no significant difference between the HTN and sham groups (Fig. 3C). T cell subsets in the HTN group were significantly different (blood, TEM $\mathrm{P}<0.05$; splenocytes, TEM and naïve T cells $\mathrm{P}<0.001)$ compared with those in the sham and control groups, whereas the other two groups exhibited no significant differences from each other 8 weeks post-surgery (Fig. 3D).

\section{Discussion}

Various cells and influencing factors are associated with the progression of hypertension. Previous studies have demonstrated that hypertension is associated with immunity. The present study assessed the changes in thymus function in mice with hypertension, and the results demonstrated that thymus functionality is significantly decreased in mice with hypertension, suggesting that the immune system is associated with the process of hypertension. Therefore, treating the thymus may improve functionality, promote immune system function and ameliorate hypertension, potentially providing a novel therapeutic target for the treatment of hypertension.

The present study demonstrated that mice with hypertension exhibited had decreased immune function due to atrophy of the thymus, based on observations of the gross thymus, thymic pathology slices, the thymus index and expression of the anti-thymus aging related gene Foxn1.

As the development and maturation of $\mathrm{T}$ cell occurs in the thymus, changes to the $\mathrm{T}$ cell subsets are also indicative of abnormal thymus function (33-35). sjTREC may be used to evaluate the output of naive $\mathrm{T}$ cells and thereby serve as a proxy for thymus output function, indirectly demonstrating thymus dysfunction (36-38). Hypertension is acknowledged to be a chronic disease $(39,40)$; however, in the present study hypertension was induced in mice via the two-kidney one-clip method only 4 or 8 weeks prior to sacrifice, which may explain why the thymic index showed no significant differences between the three groups. In future research, it may be better to allow a longer period of time between surgery and sacrifice to investigate whether the thymic index is significantly altered.

Previous studies have demonstrated that Foxn1 is exclusively expressed in the thymus (41-43). Increasing Foxn1 expression may induce partial or total recovery of thymus 
function (13); therefore, increasing the expression of Foxn1 may raise the cure rate and provide new diagnostic methods for hypertension and other immune-related diseases, such as asthenic bulbar paralysis.

A number of studies have suggested that stress may induce a decline in thymus function (44-46), by demonstrating that stress induces a transient reduction in thymus functionality; however, when individuals recover to a non-stressed state, thymus function is restored. However, these studies did not explore the mechanisms responsible for the transient effects of stress on thymus function. This may be associated with the increase of angiotensin, renin angiotensin and thyroid hormone, and may also be associated with stimulation of sympathetic nerves. Further research is required to confirm this hypothesis.

In the present study, the two-kidney, one-clip model of hypertension was used, which is secondary renal hypertension; therefore the results demonstrate that the immune system may be associated with the pathological process of renal hypertension. However, it remains to be determined whether the immune system has an association with primary hypertension and other types of secondary hypertension.

In conclusion, in vivo experiments on mice with hypertension suggest that there may be a correlation between hypertension and immune dysfunction. Improving immune system or thymus function may enhance the therapeutic effects of treatments for hypertension, which may provide a novel therapeutic target and treatment concept for treating hypertension, and potentially lead to the development of an anti-hypertension vaccine.

\section{Acknowledgements}

The present study was supported by the National Natural Science Foundation of China (grant nos. 81130065, 81072981, 30971101, 31171130 and 30900528), the Shanghai Pujiang Talent Program (D-15), the Shanghai Key Basic Research Program (grant no. 10411956,500), and the Shanghai Project of International Cooperation and Exchange (grant no. 10410701700).

\section{References}

1. Vaziri ND, Wang XQ, Oveisi F and Rad B: Induction of oxidative stress by glutathione depletion causes severe hypertension in normal rats. Hypertension 36: 142-146, 2000.

2. Vinh A, Chen W, Blinder Y, Weiss D, Taylor WR, Goronzy JJ, Weyand CM, Harrison DG and Guzik TJ: Inhibition and genetic ablation of the B7/CD28 T cell costimulation axis prevents experimental hypertension. Ccirculation 122: 2529-2537, 2010.

3. Cavasin MA, Liao TD, Yang XP, Yang JJ and Carretero OA: Decreased endogenous levels of Ac-SDKP promote organ fibrosis. Hypertension 50: 130-136, 2007.

4. Neutel JM, Giles T, Punzi H, Weiss RJ, Li H and Finck A Long-term safety of nebivolol and valsartan combination therapy in patients with hypertension: An open-label, single-arm, multicenter study. J Am Soc Hypertens 8: 915-920, 2014.

5. Ebringer A and Doyle AE: Raised serum IgG levels in hypertension. Br Med J 2: 146-148, 1970.

6. De Ciuceis C, Rossini C, La Boria E, Porteri E, Petroboni B, Gavazzi A, Sarkar A, Rosei EA and Rizzoni D: Immune Mechanisms in Hypertension. High Blood Press Cardiovasc Prev 21: 227-234, 2014.

7. Leibowitz A and Schiffrin EL: Immune mechanisms in hypertension. Curr Hypertens Rep 13: 465-472, 2011.
8. Sonmez A, Kisa U, Uckaya G, Eyileten T, Comert B, Koc B, Kocabalkan F and Ozata M: Effects of losartan treatment on T-cell activities and plasma leptin concentrations in primary hypertension. J Renin Angiotensin Aldosterone Syst 2: 112-116, 2001.

9. Walters SN, Webster KE, Daley S and Grey ST: A role for intrathymic $\mathrm{B}$ cells in the generation of natural regulatory $\mathrm{T}$ cells. J Immunol 193: 170-176, 2014.

10. Ruan L, Zhang Z, Mu L, Burnley P, Wang L, Coder B, Zhuge Q and Su DM: Biological significance of FoxN1 gain-of-function mutations during $\mathrm{T}$ and $\mathrm{B}$ lymphopoiesis in juvenile mice. Cell Death Dis 5: e1457, 2014.

11. Bredenkamp N, Ulyanchenko S, O'Neill KE, Manley NR, Vaidya HJ and Blackburn CC: An organized and functional thymus generated from FOXN1-reprogrammed fibroblasts. Nat Cell Biol 16: 902-908, 2014.

12. Zook EC, Krishack PA, Zhang S, Zeleznik-Le NJ, Firulli AB, Witte PL and Le PT: Overexpression of Foxn1 attenuates age-associated thymic involution and prevents the expansion of peripheral CD4 memory T cells. Blood 118: 5723-5731, 2011.

13. Bredenkamp N, Nowell CS and Blackburn CC: Regeneration of the aged thymus by a single transcription factor. Development 141: 1627-1637, 2014.

14. Fukuda S, Tsuchikura S and Iida H: Age-related changes in blood pressure, hematological values, concentrations of serum biochemical constituents and weights of organs in the SHR/Izm, SHRSP/Izm and WKY/Izm. Exp Anim 53: 67-72, 2004.

15. Lovewell TR, McDonagh AJ, Messenger AG, Azzouz M and Tazi-Ahnini R: The AIRE-230Y Polymorphism affects aire transcriptional activity: Potential influence on aire function in the thymus. PLoS One 10: e0127476, 2015.

16. Liston A, Gray DH, Lesage S, Fletcher AL, Wilson J, Webster KE, Scott HS, Boyd RL, Peltonen L and Goodnow CC: Gene dosage-limiting role of Aire in thymic expression, clonal deletion, and organ-specific autoimmunity. J Exp Med 200: 1015-1026, 2004.

17. Berthiaume F, Aparicio CL, Eungdamrong J and Yarmush ML: Age- and disease-related decline in immune function: An opportunity for 'thymus-boosting' therapies. Tissue Eng 5: 499-514, 1999.

18. Lang PO, Govind S, Dramé M and Aspinall R: Measuring the TREC ratio in dried blood spot samples: Intra- and inter-filter paper cards reproducibility. J Immunol Methods 389: 1-8, 2013.

19. Lynch HE and Sempowski GD: Molecular measurement of T cell receptor excision circles. Methods Mol Biol 979: 147-159, 2013.

20. Hug A, Korporal M, Schröder I, Haas J, Glatz K, Storch-Hagenlocher B and Wildemann B: Thymic export function and $\mathrm{T}$ cell homeostasis in patients with relapsing remitting multiple sclerosis. J Immunol 171: 432-437, 2003.

21. Sodora DL, Douek DC, Silvestri G, Montgomery L, Rosenzweig M, Igarashi T, Bernacky B, Johnson RP, Feinberg MB, Martin MA and Koup RA: Quantification of thymic function by measuring $\mathrm{T}$ cell receptor excision circles within peripheral blood and lymphoid tissues in monkeys. Eur J Immunol 30: 1145-1153, 2000.

22. Chiarini M, Sottini A, Bertoli D, Serana F, Caimi L, Rasia S, Capra R and Imberti L: Newly produced T and B lymphocytes and T-cell receptor repertoire diversity are reduced in peripheral blood of fingolimod-treated multiple sclerosis patients. Mult Scler 21: 726-734, 2015 .

23. Al-Harthi L, Marchetti G, Steffens CM, Poulin J, Sékaly R and Landay A: Detection of T cell receptor circles (TRECs) as biomarkers for de novo $\mathrm{T}$ cell synthesis using a quantitative polymerase chain reaction-enzyme linked immunosorbent assay (PCR-ELISA). J Immunol Methods 237: 187-197, 2000.

24. Jiménez PM, Conde C, Casanegra A, Romero C, Tabares AH and Orías M: Association of ACE genotype and predominantly diastolic hypertension: A preliminary study. J Renin Angiotensin Aldosterone Syst 8: 42-44, 2007.

25. Campagnaro BP, Gava AL, Meyrelles SS and Vasquez EC: Cardiac-autonomic imbalance and baroreflex dysfunction in the renovascular Angiotensin-dependent hypertensive mouse. Int J Hypertens 2012: 968123, 2012.

26. Zhou YB, Sun HJ, Chen D, Liu TY, Han Y, Wang JJ, Tang CS, Kang YM and Zhu GQ: Intermedin in paraventricular nucleus attenuates sympathetic activity and blood pressure via nitric oxide in hypertensive rats. Hypertension 63: 330-337, 2014

27. Wei Z, Spizzo I, Diep H, Drummond GR, Widdop RE and Vinh A: Differential phenotypes of tissue-infiltrating $T$ cells during angiotensin II-induced hypertension in Mice. PLoS One 9: e114895, 2014 
28. Guzik TJ, Hoch NE, Brown KA, McCann LA, Rahman A, Dikalov S, Goronzy J, Weyand C and Harrison DG: Role of the $\mathrm{T}$ cell in the genesis of angiotensin II-induced hypertension and vascular dysfunction. J Exp Med 204: 2449-2460, 2007.

29. Livak KJ and Schmittgen TD: Analysis of relative gene expression data using real-tie quantitative PCR and the 2(-Delta Delta C(T)) Method. Methods 25: 402-408, 2001.

30. Ortman CL, Dittmar KA, Witte PL and Le PT: Molecular characterization of the mouse involuted thymus: Aberrations in expression of transcription regulators in thymocyte and epithelial compartments. Int Immunol 14: 813-822, 2002.

31. McDonald CA, Payne NL, Sun G, Moussa L, Siatskas C, Lim R, Wallace EM Jenkin G and Bernard CC: Immunosuppressive potential of human amnion epithelial cells in the treatment of experimental autoimmune encephalomyelitis. J Neuroinflammation 12: 112, 2015.

32. Ammirati E, Cianflone D, Vecchio V, Banfi M, Vermi AC, De Metrio M, Grigore L, Pellegatta F, Pirillo A, Garlaschelli K, et al: Effector memory t cells are associated with atherosclerosis in humans and animal models. J Am Heart Assoc 1: 27-41, 2012.

33. Bernardi AI, Andersson A, Stubelius A, Grahnemo L, Carlsten $\mathrm{H}$ and Islander U: Selective estrogen receptor modulators in $\mathrm{T}$ cell development and $\mathrm{T}$ cell dependent inflammation. Immunobiology 220: 1122-1128, 2015.

34. Petrie HT: Cell migration and the control of post-natal T-cell lymphopoiesis in the thymus. Nat Rev Immunol 3: 859-866, 2003.

35. Klausmann S, Sydler T, Summerfield A, Lewis FI, Weilenmann R, Sidler $\mathrm{X}$ and Brugnera E: T-cell reprogramming through targeted $\mathrm{CD} 4$-coreceptor and $\mathrm{T}$-cell receptor expression on maturing thymocytes by latent Circoviridae family member porcine circovirus type 2 cell infections in the thymus. Emerg Microbes Infect 4: e15, 2015.

36. Ringhoffer S, Rojewski M,Döhner H, Bunjes D and Ringhoffer M T-cell reconstitution after allogeneic stem cell transplantation: Assessment by measurement of the sjTREC/ $\beta$ TREC ratio and thymic naïve T cells. Haematologica 98: 1600-1608, 2013.

37. Ou XL, Gao J, Wang H, Wang HS, Lu HL and Sun HY: Predicting human age with bloodstains by sjTREC quantification. PLoS One 7: e42412, 2012.
38. Douek DC, McFarland RD, Keiser PH, Gage EA, Massey JM, Haynes BF, Polis MA, Haase AT, Feinberg MB, Sullivan JL, et al: Changes in thymic function with age and during the treatment of HIV infection. Nature 396: 690-695, 1998.

39. Feng YJ, Wang HC, Li YC and Zhao WH: Hypertension screening and follow-up management by primary health care system among chinese population aged 35 years and above. Biomed Environ Sci 28: 330-340, 2015.

40. Yang PR, Shih WT, Chu YH, Chen PC and Wu CY: Frequency and co-prescription pattern of Chinese herbal products for hypertension in Taiwan: A Cohort study. BMC Complement Altern Med 15: 163, 2015.

41. Romano R, Palamaro L, Fusco A, Giardino G, Gallo V, Del Vecchio L and Pignata C: FOXN1: A master regulator gene of thymic epithelial development program. Front Immunol 4: 187, 2013.

42. Romano R, Palamaro L, Fusco A, Iannace L, Maio S, Vigliano I, Giardino G and Pignata C: From murine to human nude/SCID: the thymus, T-cell development and the missing link. Clin Dev Immunol 2012: 467101, 2012.

43. Jin X, Nowell CS, Ulyanchenko S, Stenhouse FH and Blackburn CC: Long-Term Persistence of functional thymic epithelial progenitor cells in vivo under conditions of low FOXN1 expression. PLoS One 9: e114842, 2014

44. Misa-Agustiño MJ, Leiro-Vidal JM, Gomez-Amoza JL, Jorge-Mora MT, Jorge-Barreiro FJ, Salas-Sánchez AA, Ares-Pena FJ and López-Martín E: EMF radiation at $2450 \mathrm{MHz}$ triggers changes in the morphology and expression of heat shock proteins and glucocorticoid receptors in rat thymus. Life Sci 127: $1-11,2015$.

45. Gupta S, Haldar C and Ahmad R: Photoperiodic regulation of nuclear melatonin receptor ROR $\alpha$ in lymphoid organs of a tropical rodent Funambulus pennanti: Role in seasonal oxidative stress. J Photochem Photobiol B 142: 141-153, 2015.

46. Novoselova EG, Lunin SM, Khrenov MO, Parfenyuk SB, Novoselova TV, Shenkman BS and Fesenko EE: Changes in immune cell signalling, apoptosis and stress response functions in mice returned from the BION-M1 mission in space. Immunobiology 220: 500-509, 2015. 